\title{
Despite anthropogenic disturbance and moderate climate changes fish density and biomass fluctuated non directionally in a small stream
}

\author{
Tadeusz PENCZAK ${ }^{*}$
}

Department of Ecology and Vertebrate Zoology, Faculty of Biology and Environmental Protection, University of Łódź, 12/16 Banacha Str., 90-237 Łódź, Poland

*Corresponding author: penczakt@biol.uni.lodz.pl

\begin{abstract}
Quantitative fish sampling, which allows the estimation of the density and standing crop, was conducted annually in October over 23 years in a small lowland stream (Poland), which was initially natural (10 years), and then channelized (13 years). Some climatic variables (temperature and precipitation, measured daily) were available for each year of the study. Neither the state of stream channelization nor the climatic variables were significantly correlated with the total density of fish species (N) and their standing crop (SC) in the stream, during study period. Individually investigated species did not respond positively or negatively to channelization and fluctuations in air temperature and precipitation. This can be important information for managers and scientists who deal with the protection of fish in streams.
\end{abstract}

Key words: Density, biomass, local climate, stream channelization.

Received: August 2014. Accepted: October 2014.

\section{INTRODUCTION}

One of the historical hypotheses is that fish abundance in fluvial ecosystems is mostly dependent on ambient water (and thus indirectly on air) temperature and water discharge (Fry, 1971; Horwitz, 1978). In temperate zones, it has been suggested that seasonal climatic changes affect wild fish populations both quantitatively and qualitatively (Harvey, 1987; Matthews, 1998; Jackson et al., 2001). Research on responses of individual species to water temperature identified the dependence of population abundance on water temperature was undertaken also (Le Cren, 1958; Craig and Kipling, 1983; Shuter et al., 1989). However, many riverine species of a temperate zone are resistant and adapted to unstable climatic conditions (particularly, in a short period of time), which do not cause high mortality such as that caused by toxic substances released into rivers, for example (Allan, 1995; Matthews, 1998; Kruk and Penczak, 2013).

Investigation of the effect of river channelization on fish populations also has a long history and delivered a lot of convincing evidence that a reconstruction of the river bed (which changes the natural discharge) can have a negative impact on the qualitative and a quantitative composition of the fish fauna (Smith, 1963; Harper and Ferguson, 1995 (see Frontispiece in the book); Penczak et al., 1998) and their food base (Smith et al., 1984; Gore, 1985; Gore et al., 2008). Hodgson and O'Hara (1994) who examined the effect of channelization on fish populations in the Welsh Dee River stated that in the shallow that appeared after the reg- ulation river salmon movement was made difficult, which affected anglers' catches. However after the conducted channelization they did not observe deleterious changes in the coarse fish populations' abundances. It is not easy to identify an impact of climate on the abundances (or biomasses) of species because they are simultaneously impacted by biotic factors also (Shuter and Meisner, 1992; Mann, 1994; Grossman et al., 1990; Jackson et al., 2001; Głowacki and Penczak, 2013; Nielsen et al., 2013). Many studies indicate that biological factors exclusively can also drive significant fluctuations in fish species density in a stream (Mills, 1982; Henderson, 1985; Wootton, 1985; Copp et al., 1991; Persson and Johansson, 1992; Mann, 1994; Penczak, 1994, Jackson et al., 2001; Nielsen et al., 2013). Fluctuations in fish species abundance have been frequently recorded not only in the total fish of a stream but in the abundance of an individual species' year-classes (Matthews, 1998; Głowacki and Penczak, 2012), when reproduction and then recruitment $(0+)$ were affected by many biotic and abiotic factors (Wootton, 1985; Mann, 1994; Jackson et al., 2001; Penczak, 2001). Some study indicate that the frequent mass mortality of juveniles, can result from low temperature and starvation, may be caused by unfavourable temperatures, and when the food required by the fish (some developmental stages of macroinvertebrates) does not appear at the appropriate time (Shuter $e t$ al., 1989; MacLean et al., 1981; Mills, 1982; Henderson, 1985; Mills and Mann, 1985; Johnson and Evans, 1991; Persson and Johansson, 1992; Jackson et al., 2001; Grossman, 2013). Juvenile fish respond with immediate and mass 
mortality to the above mentioned factors. This is because $0+$ fish have 'narrow and specific requirements' (Wootton, 1985), and the absence of conditions that satisfy these requirements can significantly reduce or even stop the recruitment of a species' cohort in a given year (Schiemer et al., 1991; Penczak, 1994). Consequently, 0+ fish can provide a direct indication of environmental conditions (Copp et al., 1991), which is compatible with the observation that in many species new strong cohorts enter a population only from time to time, and rarely every year (Penczak, 1994; Mann, 1994).

The aim of the study was to show how stable are density and biomass of fish in a small stream derived by climate change and the stream channelization. An additional aim was to determine if there were any individual species responding either positively or negatively (unambiguously) to the two factors abovementioned.

\section{METHODS}

\section{Study area}

Fish samples were collected in the Dobrzynka Stream (21 km long), tributary of the Ner River in the Warta River system (Poland), in the first half of October of each year. The study was conducted in the middle reaches of the stream, over $2.5 \mathrm{~km}$ upstream from the 70 thousand inhabitant industrial city Pabianice (Fig. 1), where the right bank

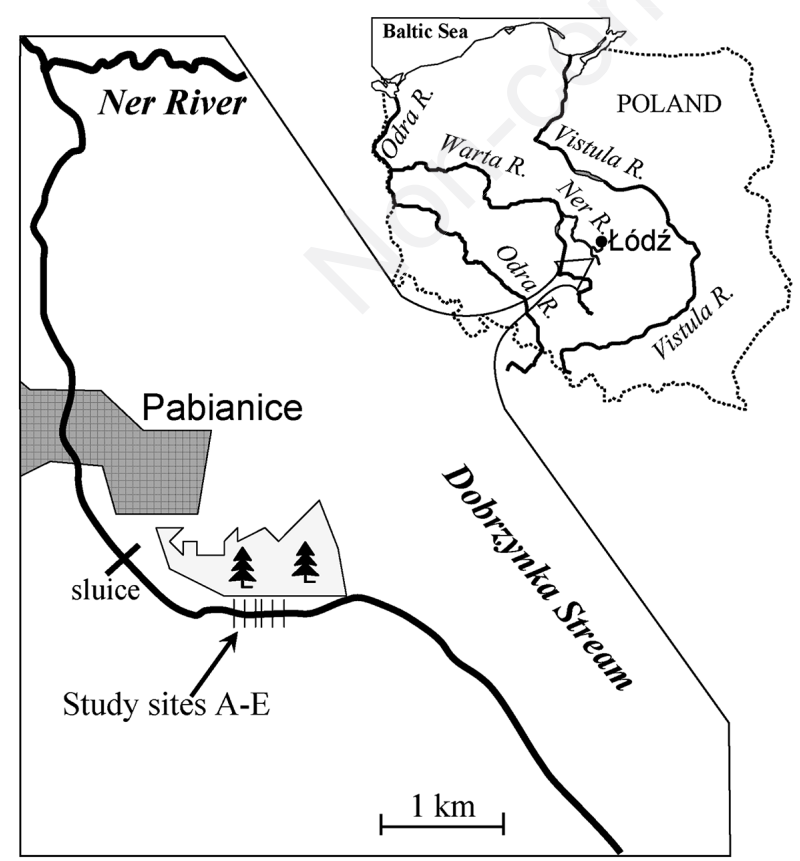

Fig. 1. Map of the Dobrzynka Stream (Poland), and sampling sites (A-E) location. Site A is located downstream, site $\mathrm{C}$ is only $50 \mathrm{~m}$ long, remaining ones are $100 \mathrm{~m}$ each. of the stream adjoined forest, and the left edge a $0.5-1 \mathrm{~km}$ belt of meadows and pastures, not very intensively used.

The stream was flowing in a natural riverbed at the beginning of the present investigations (1979-1988), but has been channelized since the spring of 1989. However, the channelization work was carried out so fast that in October 1989, when our fish sample of that year was collected, no sign of the channelization works was already visible. The channelization consisted in the modification of meanders, either by their removal or by decreasing their angles, in the construction of several cement weirs, in the clearance of all vegetation, including trees, shrubs, submerged and emerged plants, and in the construction of fascine fences (wicker wall built of osier branches) along each bank of the study area section, and elsewhere in that course of the river. The channel width and depth were uniform, and the stream resembled a ditch (1.7 $\mathrm{m}$ in width).

The positions of the five sampling sites (A-E) are marked on Fig. 1. The sites were designated as a $450 \mathrm{~m}$ stretch that did not differ morphologically from adjacent parts of the stream, and were considered to be representative of the middle reaches of the Dobrzynka Stream. However, the $450 \mathrm{~m}$ stretch was not representative for the whole length of the $21 \mathrm{~km}$ long stream when the study began (1979). The stream's downstream course was a 6 $\mathrm{km}$ stretch that was fishless, because it served as the collector of chemical, textile and domestic wastewater that was drained the whole of the Pabianice town. The stream section from the sources to set out sites was about $11 \mathrm{~km}$ long and for the first $5 \mathrm{~km}$ stream flowed and still flows through the forest. The mean water discharge on the sampling days (in October of 1979-2001) was $0.15 \mathrm{~m}^{3} \mathrm{~s}^{-1}$ $\left(0.10-0.26 \mathrm{~m}^{3} \mathrm{~s}^{-1}\right)$; mean water discharge also did not change significantly after the stream channelization.

Air temperature and precipitation, which were measured daily by a governmental unit located close to the mouth of the Dobrzynka Stream. For these two variables, monthly average values were calculated, and from them the yearly averages, averages for the winter months (NovApr), and for the summer months (May-Oct). The decision to use these data for the estimation of climate changes follows Crisp (1992), who found high correlations between mean water temperature and mean air temperature in small temperate zone streams, and a high correlation between precipitation and discharge. Accordingly, his study allows the prediction of stream water temperatures from air temperatures, which was confirmed by Mann (1976). Since the Dobrzynka Stream flows across a flat valley, rain does not cause any significant increase in discharge over a short period of time. In such conditions, air temperature and precipitation are adequate for estimating the effect of discharge and water temperature on fish populations (Mann, 1976). 


\section{Sampling}

In the course of electrofishing, two people waded six times upstream with anode dipnets along each site. Sites $\mathrm{A}, \mathrm{B}, \mathrm{D}$, and $\mathrm{E}$ were $100 \mathrm{~m}$ long, site $\mathrm{C}$ was $50 \mathrm{~m}$ long (Fig. 1). Caught fish from each sample, after the identification of the species were counted, weighed and released back into the river at the end of given site. Site area of sites A, B, D and E till 1988 was over $200 \mathrm{~m}^{2}$ each, and after channelization about $170 \mathrm{~m}^{2}$ each; that of site $\mathrm{C}$ was $85 \mathrm{~m}^{2}$ (Penczak and Głowacki, 2008). For this study, fish were sampled at the first ten day period of October, each year from 1979 to 2001, because this month freshwater fish in middle Europe achieve their maximum length, body weight, body caloricity, etc. (Wootton, 1985). Fullwave rectified current was supplied from a $3 \mathrm{~kW}$ generator with an output of 220-230 V and 1.5-3.0 A at the dipnets.

\section{Data analysis}

The depletion method of abundance estimation was used to estimate the density, the standing crop (sensu Ricker, 1968), catchability and other parameters (Zippin, 1956). Application of the Zippin model is exemplified in a paper devoted to fish catchability in the Dobrzynka Stream (Penczak and Głowacki, 2008). The density and standing crop for all populations and some selected species were recalculated per $100 \mathrm{~m}^{2}$ using means from the four sampled sites, which were $100 \mathrm{~m}$ long, and the central site $(\mathrm{C})$, which was $50 \mathrm{~m}$ long.

The randomization test was used to assess a null hypothesis of no difference in population parameters (mean density and biomass) between the natural and regulated stream (Efron and Tibshirani, 1993). The Spearman rank correlation analysis was applied to search for relations between precipitation and temperature versus density, and versus biomass (Zar, 2010). The correlation analysis was also carried out using abundance and density data that lagged one year behind the precipitation and temperature data, to quantify temporal variation in the patterns of the populations (Collins et al., 2000; Kampichler and van der Jeugd, 2013).

\section{RESULTS}

Density increased between 1988 and 1990, and remained high for two subsequent years. In 1993, it decreased to the level recorded before channelization (Fig. 2). Similarly biomass increased between 1989 and 1991 but in 1993 it was at the level observed before the channelization. The stream channelization did not seem to be responsible for the fluctuations in density and biomass in the post-channelization period, and differences between investigated fish population parameters of both periods were not significant (Tab. 1).

Air temperatures for the whole year, for the summer season (May-Oct), for the winter season (Nov-Apr), and for one year time lag, did not exert any impact on the density and biomass (Tab. 2). Precipitation for the whole year, and for May-Oct period were barely significantly correlated with biomass only. The three years of the highest precipitation and mean air temperature did not coincide with the peaks of density and standing crop (Fig. 2). Data for individual species are shown in Fig. 3. There were no species for which the data suggested that density was affected by the Dobrzynka Stream channelization. Zero densities were recorded in both the unmodified and the regulated forms of the stream for: crucian carp [Carassius carassius (L.)], Ukrainian lamprey [Eudontomyzon mariae (Berg)], and bitterling [Rhodeus sericeus (Pallas)]. Densities were $\leq 5$ individuals per $100 \mathrm{~m}^{2}$ for perch (Perca fluviatilis L.), roach [Rutilus rutilus (L.)], crucian carp, and Ukrainian lamprey. Gibel carp [Carassius gibelio (Bloch)] was absent between 1979 and 1987 (i.e., in the natural stream), but present in 1988, when the stream still had a natural corridor, at densities of $\leq 5$ individuals per $100 \mathrm{~m}^{2}$. The species was abundant in the first years after the channelization, yet in the two following years they became rare again. A similar situation occurred for crucian carp, had its highest population densities in the natural stream. Similar patterns were observed for Ukrainian lamprey, bitterling, sunbleak [Leucaspius delineates (Heckel)], and ten-spined stickleback [Pungitius pungitius (L.)], whose highest densities occurred in the natural corridor. For all these species, zero and the lowest densities were also recorded in both the natural and engineered habitats (Fig. 3). Perch, roach, gudgeon [Gobio gobio (L.)], stone loach (Barbatula barbatula) and stickleback (Gasterosteus aculeatus L.) reached their highest densities one year after the channelization, yet after 1993 their abundance returned to a medium, or more frequently to a lower level, than in the natural stream.

Gudgeon (bentic, psammophilous species) was the most abundant species and was collected in all years of the study (occurrence stability: 100\%), while less abundant but always present were the stone loach, three-spined stickleback and ten-spined stickleback, which in 1979-

Tab. 1. Randomization test comparing the mean values of the density and standing crop of all populations of fish species in the pre- and post-regulation periods.

\begin{tabular}{lcc} 
Parameters & Ne $100 \mathrm{~m}^{2}$ & Be $100 \mathrm{~m}^{2}$ \\
N. of replications & 10,000 & 10,000 \\
Total of sample A & 3274.3 & 17791.9 \\
\hline Total of sample B & 3260.3 & 25935.8 \\
Mean of sample A & 327.4 & 1779.2 \\
\hline Mean of sample B & 250.8 & 1995.1 \\
Difference between means (A-B) & 76.7 & -215.9 \\
\hline Null hypothesis: A=B (two-tailed test) & & \\
P value & 0.3378 & 0.5871 \\
\hline
\end{tabular}

Ne, density; Be, standing crop; A, pre-regulation period; B, post-regulation period. 
Tab. 2. Spearman correlations analysis between precipitation or temperature, versus density and standing crop. Climate parameters were calculated from monthly means.

\begin{tabular}{|c|c|c|c|c|}
\hline Precipitation & Valid & Spearman & $t(N-2)$ & $\mathbf{P}$ \\
\hline Whole year and $\mathrm{Ne}$ & 23 & -0.3711 & -1.8315 & 0.0812 \\
\hline Whole year and $\mathrm{Be}^{*}$ & 23 & -0.4972 & -2.6257 & 0.0157 \\
\hline May-Oct and $\mathrm{Ne}$ & 23 & -0.3656 & -1.8001 & 0.0862 \\
\hline May-Oct and $\mathrm{Be}^{* *}$ & 23 & -0.5702 & -3.1804 & 0.0045 \\
\hline Nov-Apr and $\mathrm{Ne}$ & 23 & -0.2783 & -1.3278 & 0.1985 \\
\hline Nov-Apr and Be & 23 & -0.1379 & -0.6381 & 0.5303 \\
\hline Nov-Apr, one year lag and $\mathrm{Ne}$ & 22 & 0.0938 & 0.4213 & 0.6780 \\
\hline Nov-Apr, one year lag and Be & 22 & 0.1249 & 0.5628 & 0.5798 \\
\hline \multicolumn{5}{|l|}{ Air temperature } \\
\hline Whole year and $\mathrm{Ne}$ & 23 & -0.0401 & -0.1838 & 0.8559 \\
\hline Whole year and $\mathrm{Be}$ & 23 & 0.1633 & 0.7584 & 0.4566 \\
\hline May-Oct and $\mathrm{Ne}$ & 23 & -0.1809 & -0.8429 & 0.4087 \\
\hline May-Oct and Be & 23 & 0.0397 & 0.1818 & 0.8574 \\
\hline Nov-Apr and $\mathrm{Ne}$ & 23 & 0.0618 & 0.2838 & 0.7793 \\
\hline Nov-Apr and Be & 23 & 0.3027 & 1.4553 & 0.1604 \\
\hline Nov-Apr, one year lag and $\mathrm{Ne}$ & 22 & 0.2323 & 1.0680 & 0.2982 \\
\hline Nov-Apr, one year lag and Be & 22 & 0.2611 & 1.2096 & 0.2405 \\
\hline
\end{tabular}

Ne, density; Be, standing crop. Significance level: ${ }^{*} \leq 0.05,{ }^{* *} \leq 0.01$.
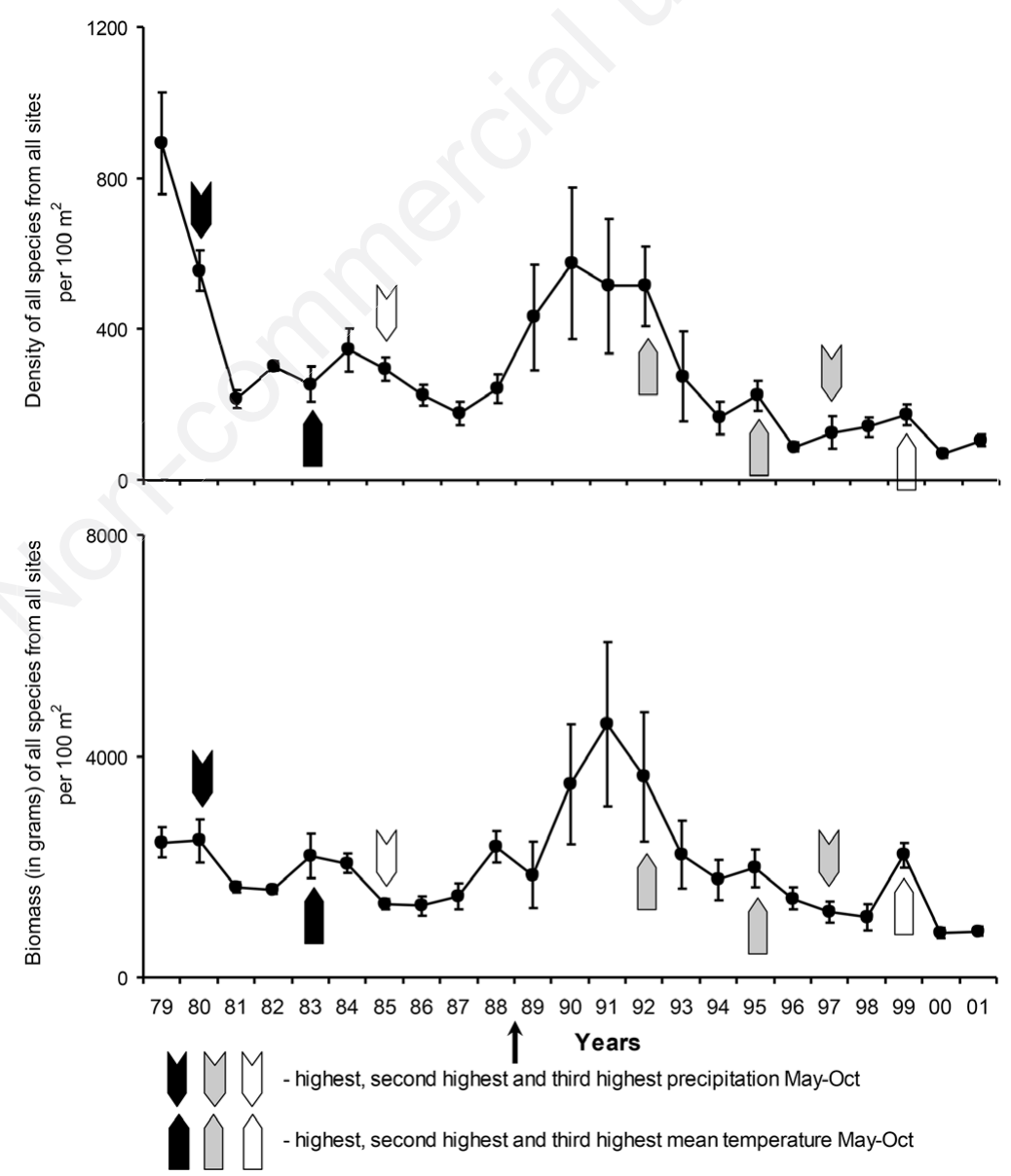

Fig. 2. Variability and fluctuations of the density and standing crop (SC) for all of the species together during the sampling time (mean \pm standard error) in the Dobrzynka Stream (Poland). The density and SC were calculated per $100 \mathrm{~m}^{2}$ from five, adjoining, sampled sites. The arrow indicates the year in which stream channelization began. 
1980 was the predominating species in the Dobrzynka Stream, although afterwards it became rare (Fig. 3), with two exceptions in 1985 and 1995. Species such as perch and roach were both absent once, in 1979. There were species that were rarely sampled in the natural corridor (gibel, carp), or the channelized one (Ukrainian lamprey, bitterling, and sunbleak). However, no species either appeared or became extinct precisely in 1989 spring, when canalization was performed (Fig. 3). Some species were even more abundant in 1989, but none reached a density that had not been recorded in the natural stream already.

\section{DISCUSSION}

In the present study, one density peak was observed at the beginning (Fig. 2), and a next one eight years later (1990-92). The second density peak was not induced by the stream channelization, but arose after the change, one year later than a peak in standing crop. The peak of density (in 1979-80) indicates that rich 0+ cohorts were entering the fish populations because of the low total standing crop values (with numerous new $0+$ cohorts of low mean body weight). Large fluctuations (up to 10-fold)
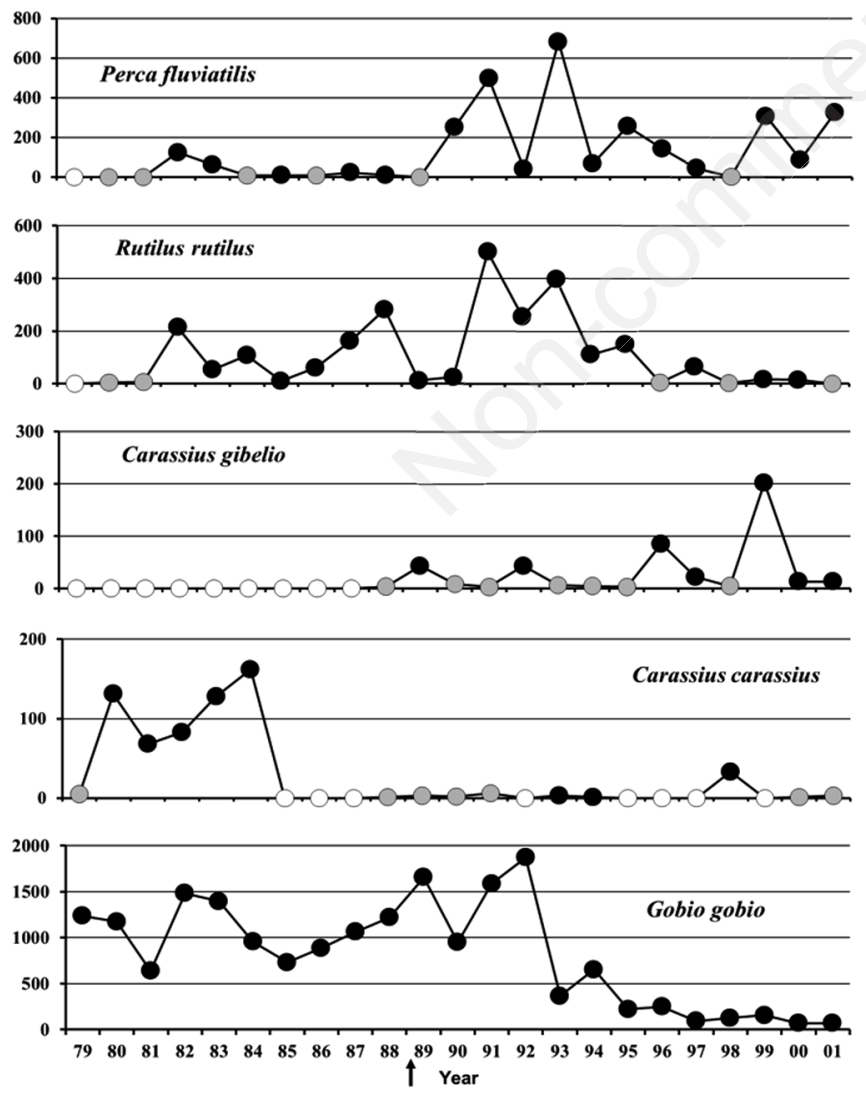

Fig. 3. Fluctuations of the density per $100 \mathrm{~m}^{2}$ of common species in the Dobrzynka Stream (Poland). White circles indicate absence of fish, while grey ones indicate presence of less than 5 individuals.
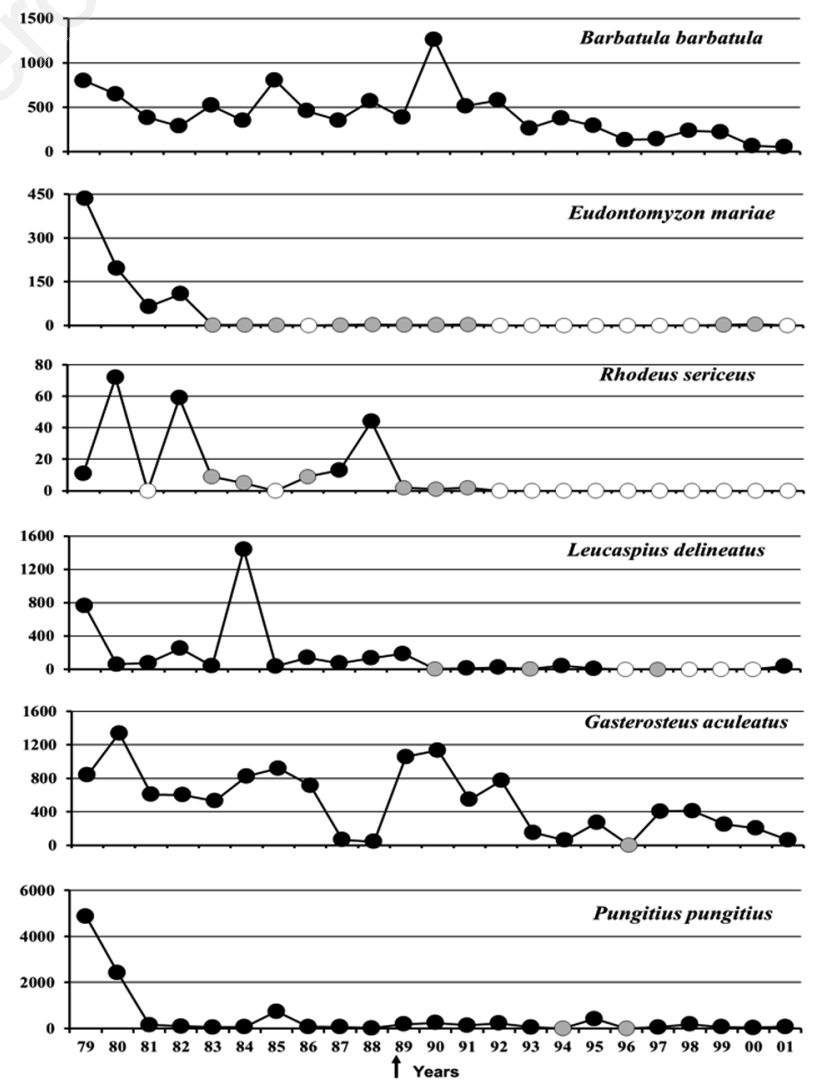

in fish numbers in the Sagehen Creek (California, USA) were recorded by Gard and Flittner (1974) during a nine year study only. A dataset spanning 40 years (1969-2008) obtained in southern Oklahoma streams by Matthews et al. (2013), shows that most species were persistent, qualitatively, across the whole period, but varied widely in abundance. Presumably future studies will be able to answer whether population explosions can take place every few years and have a cyclical or stochastic character (Grossman et al., 1990). The high variability recorded in stream fish assemblages suggests that it may be hardly possible to detect the impact of anthropogenic using population data only (Grossman et al., 1990).

The inability to demonstrate the negative impact of channelization of the Dobrzynka Stream on the fish populations could be caused by the fact that the planks that were inserted in the weirs' slots for damming water were sides, three-four years after the river banks were strengthened with fascine to protect them against erosion in 1989 , running water (in a few places), had much destroyed the wicker walls and had dug cavities around the poles stuck into the bottom that served as the walls' support, thus hav- 
ing formed shelters for fish there (Penczak and Mann, 1993). Despite of the above data some effects of channelization conducted in the middle course of the Dobrzynka Stream were expected because several low cement weirs were constructed there, and the clearance of all submerged and emerged vegetation was performed (Penczak and Głowacki, 2008). This resistance fish populations against extinction can be continues even when rivers become regulated (Shuter and Meisner, 1992; Jackson et al., 2001; Parasiewicz, 2008), for example when naturally vegetated banks are replaced by concrete slabs (Wootton, 1990; Matthews, 1998; Jackson et al., 2001).

Reactions of individual species to the stream channelization were different and not simultaneously dependent on the channelization. The reactions were difficult to explain by climatic changes. Some studies of a single species have suggested that abundance/density peaks are not clearly related to climate and visible during one-two decades interval (Rose, 2000; Penczak, 2011; Matthews et al., 2013). Biomass and density for the whole year, summer, winter, and one year lagged whole year, were not significantly correlated with temperature (Tab. 2). Precipitation with the whole year biomass and the summer months biomass were correlated on barely significant levels (Zar, 2010). Probably the larger precipitation, resulting in a faster water flow, rinsed part of the fish down the stream, and this produced a negative correlation. Yet these analyses do not indicate that co-occurrence patterns between the species were present, with the resulting possibility of biotic interactions (predation and competition) being responsible for strong fluctuations in density (Grossman et al., 1990; Céréghino et al., 2005) .

It is still difficult to determine the time required to assess the environmental variables that could change a species' abundance (Głowacki and Penczak, 2012). The effects of a particular disturbance on a species may require a long period of time to become detectable (Power et al., 1996; Matthews, 1998; Głowacki and Penczak, 2013). The present study could not explain peaks and troughs in fish density and standing crop. The most abundant species, such as stony loach, stickleback, perch, and gudgeon, were present each year, but fluctuated in number from year to year, as in other Polish rivers (Penczak et al., 1998, 2007). All species combined, as well as individual species, did not respond to such stressors as the stream channelization and climate changes at any significant level in the Dobrzynka Stream. This may be partly explained by the fact that dominant and subdominant species in the Dobrzynka Stream have calculated median displacement (MD) close or smaller than the home section lengths (HSL: $100 \mathrm{~m}$, sensu Gerking, 1959), with exception of gibel on one sampling occasion. These results were congruent with estimated low turnover rate (TR) for the investigated species, which was significantly correlated with MD, and congruent with the Gerking's restricted movement paradigm (RMP), which was tested directly in this stream (Penczak, 2005).

The result of this study can be considered a warning to efforts that attempt to estimate a population's persistence and stability on the basis of a few year study, even when applying sufficient sampling methods (Simonson and Lyons, 1995; Grossman et al., 1990; Pusey et al., 1998; Gotelli et al., 2010). Grossman et al., (1990) urge managers and scientists to exercise caution in the estimation of the effects of anthropogenic disturbance on the populations' parameters, and they suggests more long-term studies in this matter. The dynamics of the density and standing crop fluctuations of some species may be so slow that there are doubts whether a few years' data may be representative enough for any stream or other freshwater habitat (Gard and Flittner, 1974; Grossman et al., 1990; Matthews, 1998; Jackson et al., 2001; Collins et al., 2000; Collie et al., 2008; Gore et al., 2008; Beugly and Pyron, 2010). Some published data indicate that a large population increase in some species may occur in a stream because of favourable feeding conditions along the stream (Mills and Mann, 1985), which then strongly affects spawning success, and low mortality of both juveniles and adults (Mann et al., 1984; Mann, 1994; Allan, 1995; Matthews, 1998).

The answer to the title of the work is that species of fish in the stream, which in the meantime was canalized, and the climate also was changing, were subject to considerable fluctuations, which cannot be clearly explain, despite of fact that sampling methods were uniform during the whole study period, which is a requirement of reliable and efficient monitoring, as stated by Spellerberg (1991). Hence, not without significance is the fact that fish densities and standing crop were also standardized per constant unit of area, which increases the reliability of this study. Quantitative sampling methods were used in the study because Gotelli et al. (2010), stated that qualitative sampling techniques may have importance for fluctuation research.

\section{CONCLUSIONS}

According to Nielsen et al., (2013), climate impact alone and in a short time will not allow for an accurate prediction of the range of salmon in the Arctic, due to the complexity of the adaptive response and biological interactions that factor in successful colonization; moreover, it seems to also present a limitation for other fish, especially in freshwater. In our study, air temperatures for the whole year, the summer season, the winter season, and for a one-year time lag, did not exert significant impact on the density and biomass (Tab. 2). Precipitation for the whole year, and for the May-Oct period, was barely significantly correlated with biomass only. The three years of the highest precipitation and mean air temperature did not coincide with the peaks of density and standing crop (Fig. 2). Also, the stream reg- 
ulation did not appear to be responsible for fluctuations in density and biomass in the post-regulation period (Tab. 1). Density and biomass increased between 1988 and 1990, and then remained high for two subsequent years. In 1993, it decreased to the level recorded before regulation (Fig. 2).

Nothing was also found following the fate of individual species between the two studied parameters concerning the climate as well as regulation of the Dobrzynka Stream, occurring during mid-term in the research (Fig. 3). There were no species whereby the data suggested that density was affected by regulation of the Dobrzynka Stream. Zero densities were recorded in both the unmodified and the regulated stream for the majority of species. Grossman et al. (1990) stated that it may be difficult to detect the effects of anthropogenic disturbance using population data alone.

Natural decadal variations in climate can mask anthropogenic effects and warming at regional scales for years or even decades into the future (Głowacki and Penczak, 2013). A multifarious approach is needed that combines physical, environmental and ecological factors with the expansion of the species' range at the species, population and individual levels. According to Nielsen et al. (2013), this will require collaborations between scientists from different branches of biological sciences. Nielsen et al. (2013), when finalizing the subchapter Conclusions in their study, formulated many remaining questions without answers, and one of these also limited our study: which species are the real generalists? The reality of changing climate conditions has generated a wave of thinking where the impact on humans and other organisms causes great concern. A broad scale of climate change presumably does not correlate with short-term local conditions (Wootton, 1990).

\section{ACKNOWLEDGMENTS}

I thank Richard Johnson (UK) for the final English correction, and the anonymous referees for useful suggestions. Thanks are directed to $\mathrm{E}$. Głowacki (Poland) for drawing figures. The River Fish Ecology Team (www.ekologia.uni.lodz.pl) are thanked for their participation in the field research. This study was occasionally financially supported by the University of Łódź and the Polish Angling Association.

\section{REFERENCES}

Allan JD, 1995. Stream ecology. Structure and function of running waters. Chapman and Hall, UK: 431 pp.

Beugly J, Pyron M, 2010. Temporal and spatial variation in the long-term functional organization of fish assemblages in a large river. Hydrobiologia 654:215-226.

Céréghino R, Santoul F, Compin A, Figuerola J, Mastrorillo S, 2005. Co-occurrence patterns of some small-bodied freshwater fishes in Southwestern France: implications for fish conservation and environmental management. Ambio 34:440-444.
Collie JS, Wood AD, Jeffries HP, 2008. Long-term shifts in the species composition of a coastal fish community. Can. J. Fish. Aquat. Sci. 65:1352-1365.

Collins SL, Micheli F, Hartt L, 2000. A method to determine rates and patterns of variability in ecological communities. Oikos 9:285-293.

Copp GH, Oliver JM, Peñaz M, Roux AR, 1991. Juvenile fish as functional describes of fluvial ecosystem dynamics: application on the river Rhone, France. Regul. Rivers 6:135-191.

Craig JF, Kipling C, 1983. Reproduction effort versus the environmental; case histories of Windermere perch, Perca fluviatilis L., and pike, Esox lucius L. J. Fish Biol. 22:713-727.

Crisp DT, 1992. Measurement of stream water temperature and biological applications to salmonid fishes, grayling and dace: including ready reckoners for calculating median eyeing, hatching and swim-up of embryos, and growth rates, maximum, optimum and maintenance rations for brown trout at various temperatures. Freshwater Biological Association: 72 pp.

Efron B, Tibshirani R, 1993. An introduction to the bootstrap. Chapman \& Hall: 456 pp.

Fry FEJ, 1971. The effect of environmental factors on the physiology of fish, p. 1-98. In: W.S. Hoar and D.J. Randal (eds.), Fish physiology. 6. Academic Press.

Gard R, Flitter GA, 1974. Distribution and abundance of fish in Sagehen Creek, California. J. Wildlife Manage. 38:341-358.

Głowacki Ł, Penczak T, 2012. Large dam reservoirs are probably long-period oscillators of fish diversity. J. Fish Biol. 80:2213-2235.

Głowacki Ł, Penczak T, 2013. Drivers of fish diversity, homogenization/differentiation and species range expansions at the watershed scale. Divers. Distrib. 19:907-918.

Gerking SD, 1959. The restricted movement of fish populations. Biol. Rev. 34:221-242.

Gore JA, 1985. The restoration of rivers and streams: theories and experience Butterworth Publ.: 280 pp.

Gore JA, Mead J, Penczak T, Higler L, Kempl J, 2008. Processes influencing aquatic fauna, p. 62-87. In: D. Harper, M. Zalewski and N. Pacini (eds.), Ecohydrology: processes, models and case studies: an approach to the sustainable management of water resources. Cromwell Press.

Gotelli NJ, Dorazio RM, Ellison AM, 2010. Detecting temporal trends in species assemblages with boot strapping procedures and hierarchical models. Philos. T. R. Soc. B 365:3621-3631.

Grossman GD, 2013. Not all drift feeders are trout: a short review of fitness-based habitat selection models for fish. Env. Biol. Fish. 97:465-473.

Grossman GD, Dowd JE, Crawford M, 1990. Assemblage stability in stream fishes: a review. Environ. Manage. 5:661-671.

Harper DM, Ferguson AJD. 1995. The ecological basis for river management. J. Wiley \& Sons: 614 pp.

Harvey BC, 1987. Susceptibility of young-of-the-year fishes to downstream displacement by flooding. T. Am. Fish. Soc. 116:851-855.

Henderson BA, 1985. Factors affecting growth and recruitment of yellow perch, Perca flavescens Mitchill, in South Bay, Lake Huron. J. Fish Biol. 40:449-458.

Hodgson BP, O'Hara K, 1994. Fisheries management of the Welsh Dee - a regulated river. Pol. Arch. Hydrobiol. 41:331-345.

Horwitz RJ, 1978. Temporal variability patterns and distributional patterns of stream fishes. Ecol. Monogr. 48:307-321. 
Jackson DA, Peres-Neto PR, Olden JD, 2001. What controls who is where in freshwater fish communities - the roles of biotic, abiotic, and spatial factors. Can. J. Fish. Aquat. Sci. 58:157-170.

Johnson TB, Evans DO, 1991. Behaviour, energetics, and associated mortality of young-of-the-year white perch (Marone americana) and yellow perch (Perca flavescens) under simulated winter conditions. Can. J Fish. Aquat. Sci. 48:672-680.

Kampichler C, van der Jeugd HP, 2013. Determining patterns of variability in ecological communities: time lag analysis revisited. Environ. Ecol. Stat. 20:271-284.

Krebs CJ, 2008. Ecology: the experimental analysis of distribution and abundance, $6^{\text {th }}$ ed. Benjamin Cummings, San Francisco: $655 \mathrm{pp}$.

Kruk A, Penczak T, 2013. Natural regeneration of fish assemblages in the Pilica River after a reduction of point-source pollution. Riv. Res. Appl. 29:502-511.

Le Cren ED, 1958. Observations on the growth of perch (Perca fluviatilis) over twenty-two years, with special reference to the effects of temperature and changes in population density. J. Anim. Ecol. 27:287-334.

MacLean JA, Shuter BJ, Regier HA, MacLeod JC, 1981. Temperature and year-class strength of smallmouth bass. In: Proc. Symp. on Early Life History of Fish. Int. Council for the Exploration of the Sea, 178:30-40.

Mann RHK, 1976. Observations on the age, growth, reproduction and food of the chub Squalius cephalus (L.) in the River Stour, Dorset. J. Fish Biol. 8: 265-288.

Mann RHK, 1994. The influence of ontogeny on the response of freshwater fish to environmental variables, p. 67-77. In: M. Whitfield, J. Mathews and C. Reynolds (eds.). Aquatic life cycle strategies: survival in a variable environment. Marine Biological Association of the UK.

Mann RHK, Mills CA, Crisp DT, 1984. Geographical variation in the life-history tactics of some species of freshwater fish, p. 171-186. In: G.W. Potts and R.J. Wootton (eds.). Fish reproduction: strategies and tactics. Academic Press.

Matthews WJ, 1998. Patterns in freshwater fish ecology. Chapman \& Hall: 756 pp.

Matthews WJ, Marsh-Matthews E, Cashner RC, Gelwick F, 2013. Disturbance and trajectory of change in a stream fish community over four decades. Oecologia 173:955-969.

Mills CA, 1982. Factors affecting the survival of dace, Leuciscus leuciscus (L.), in the early post-hatching period. J. Fish Biol. 20:654-655.

Mills CA, Mann RHK, 1985. Environmentally-induced fluctuations in year-class strength and their implications for management. J. Fish Biol. 27(Suppl. A):209-226.

Nielsen JL, Ruggerone GT, Zimmerman CE, 2013. Adaptive strategies and life history characteristics in a warming climate: salmon in the Arctic? Env. Biol. Fish. 96:1187-1226.

Parasiewicz P, 2008. Habitat time-series analysis to define flow augmentation strategy for the Quinebaug River, Connecticut and Massachusetts. Riv. Res. Appl. 24:439-452.

Penczak T, 1994. Fish recruitment in the Warta River (1985-1992): impoundment study. Pol. Arch. Hydrobiol. 41:293-300.

Penczak T, 2001. Distinctness of the populations and bioenergetics indices of $0+$ fish versus older age groups in temperate zone rivers. Arch. Hydrobiol. Supplement 135/2-4:475-483.

Penczak T, 2005. Restricted-movement paradigm: fish displace- ments in a small lowland streamlet. Pol. J. Ecol. 54:145-149.

Penczak T, 2011. Fish assemblages composition in a natural, then regulated stream: a quantitative long-term study. Ecol. Modell. 222:2103-2118.

Penczak T, Głowacki Ł, 2008. Evaluation of electrofishing efficiency in a stream under natural and regulated conditions. Aquat. Liv. Res. 21:329-337.

Penczak T, Galicka W, Kruk A, Zięba G, Marszał L, Koszaliński H, Tybulczuk S, 2007. [Fish fauna in the Pilica River system in the fifth decade of study. Part II. Tributaries].[Article in Polish with English Abstract]. Sci. Ann. Pol. Angl. Assoc. 20:35-81.

Penczak T, Głowacki Ł, Galicka G, Koszaliński H, 1998. A long-term study (1985-1995) of fish populations in the impounded Warta River, Poland. Hydrobiologia 368:157-173.

Penczak T, Mann RHK, 1993. A preliminary evaluation of the effect of human activity on the fish populations of the Pilica River, Central Poland. Pol. Arch. Hydrobiol. 40:101-115.

Persson L, Johansson L, 1992. On competition and temporal variation in temperate freshwater fish populations. Neth. J. Zool. 42:304-322.

Pusey B, Kennard MJ, Arthur JM, Arthington AH, 1998. Quantitative sampling of stream fish assemblages: single- $v$ s multiple-pass electrofishing. Aust. J. Ecol. 23:365-374.

Rose KA, 2000. Why are quantitative relationships between environmental quality and fish populations so elusive ? Ecol. Appl. 10:367-385.

Ricker WE, 1968. Methods for assessment of fish production in fresh waters. 3. Blackwell Scientific: 380 pp.

Schiemer F, Spinder T, Wintersberger H, Schneider A, Chovanec A, 1991. Fish fry associations: important indicators for the ecological status of large rivers. Verh. Int. Verein. Limnol. 24:2497-2500.

Shuter BJ, Ihssen PE, Walest DJ, Snucins EJ, 1989. The effects of temperature, $\mathrm{pH}$, and water hardness on winter starvation of young-of-the-year smallmouth bass, Micropterus dolomieui Lacepede. J. Fish Biol. 35:765-780.

Shuter BJ, Meisner JD, 1992. Tools for assessing the impact of climate change on freshwater fish populations. GeoJ. 28:7-20.

Simonson TD, Lyon J, 1995. Comparison of catch per effort and removal procedures for sampling stream fish assemblages. N. Am. J. Fish. Manage. 15:419-427.

Smith PW, 1963. A study of seasonal distribution of fishes in the Kaskaskia River ditch, a highly modified stream in eastern Illinois. Copeia 1963:251-259.

Smith CD, Youdan, T, Redmond C, 1984. Practical aspects of restoration of channel diversity in physically degraded streams, p. 269-273. In: D.M. Harper and A.I.D. Ferguson (eds.), The ecological basis for river management. J. Wiley \& Sons.

Spellerberg IF, 1991. Monitoring ecological change. Cambridge University Press: 389 pp.

Wootton RJ, 1990. The ecology of teleost fishes. Chapman \& Hall: 404 pp.

Wootton RJ, 1985. Energetics of reproduction, p. 231-254. In: P. Tytler and P. Calow (eds.), Fish energetics, new perspectives. Croom Helm.

Zar, J.H. 2010. Biostatistical analysis. 5. Prentice Hall: 944 pp. Zippin C, 1956. An evaluation of the removal method of estimating animal populations. Biometrics 12:163-189. 